\title{
Management of Hatching Eggs and Broiler Performance ${ }^{1}$
}

\section{G. D. Butcher, DVM, Ph.D., Amir H. Nilipour, Ph.D. ${ }^{2}$}

Broiler performance in the field is dependent to a large extent on egg management practices. Quality management for each step of the broiler production chain involving formation of the egg, oviposition, egg handling, incubation, hatching, brooding, and broiler grow-out is essential and will affect profitability. The ultimate objective of any integration is producing high quality, healthy and vigorous chicks that have the potential to yield meat at the lowest cost per pound.

\section{Status of Flock Health}

Desired levels of egg production, high internal and shell quality of hatching eggs, optimum hatchability, and quality chicks can not be achieved when there are problems with health in the breeders. All diseases in breeders adversely affect performance, but some affect egg production and quality more severely. Diseases including infectious bronchitis, NewCastle, Mareks, Mycoplasma gallisepticum, etc. should be routinely monitored for, controlled when present with vaccines and/or antibiotics, or eliminated/prevented through biosecurity measures. Monitoring for less common diseases such as infectious laryngotracheitis, egg drop syndrome, and coryza that are not prevalent in many areas is also essential. Gastrointestinal diseases, when present, not only adversely affect egg production, but also cause diarrhea. Eggs produced will be contaminated with feces due to wet floor litter and nest box bedding, and dirty cloacas. Common sense dictates that ongoing and comprehensive biosecurity and health programs remain in practice at the breeder farm level. Any deficiencies at this stage will adversely affect production performance parameters throughout the integration.

\section{Optimum Hatching Egg Size and Sexual Maturity}

Management procedures must be reviewed to ensure that hens are raised throughout their growing cycle according to established body weight standards for the specific line. For example, hens grown to have smaller frames will produce smaller eggs that consequently produce smaller and more fragile chicks. These chicks hatched from small eggs normally experience a higher percent rate of mortality. They will grow more slowly and require a longer time to achieve projected body weights. The end result is lost pounds of poultry meat on a production unit. Ensure that breeder hens and males are provided light stimulation on time and of appropriate intensity, according to body weight and

1. This document is VM128, one of a series of the Veterinary Medicine-Large Animal Clinical Sciences Department, Florida Cooperative Extension Service, Institute of Food and Agricultural Sciences, University of Florida. Original publication date May 1, 2002. Visit the EDIS Web Site at http://edis.ifas.ufl.edu.

2. G. D. Butcher, DVM, Ph.D., Diplomate, American College of Poultry Veterinarians, University of Florida College of Veterinary Medicine, Gainesville, FL., Amir H. Nilipour, PhD, Director of Investigation and Quality Assurance, Grupo Melo, S.A., Panama, Republic of Panama 
age. Providing light stimulation to hens that do not have adequate body weight will result in the production of smaller eggs. It is recommended to monitor egg weights on a weekly basis ( 3 flats is an adequate sample). Monitoring of egg weights should be conducted throughout the production cycle and compared with the established standards provided by breeder companies.

\section{Egg Sanitation and Hatchery Hygiene}

A strict biosecurity plan should be in place and enforced for each step of the breeder-hatchery-broiler operation. The biosecurity supervisor must assure that the production farm has done an excellent job of producing clean fertile eggs. The fertile eggs must be disinfected immediately after collection and be free of obvious debris, feathers, litter shavings, stains or fecal contaminants when sent to the hatchery.

\section{Clean Nest Material}

Ensure that a sanitation program is in place and enforced and that optimum quality nest litter material is used. It has been demonstrated that a gram of contaminated litter can have up to $600,000,000$ microorganisms and these cannot be seen with the naked eye. Using high quality litter material and practicing good litter management can significantly reduce percent of dirty eggs and contamination, explosions, and second quality chicks. The percent contamination of hatching eggs should not exceed $0.5 \%$ in any hatch. The percent of eggshell contamination increases with age of the breeders, resulting from thinning of egg shells as egg size increases and increased bacterial load in the house. Thus it is suggested to double the disinfectant dosage in the egg sanitizing spray used on eggs from breeders after after 55 weeks of age. Exploders should be removed by 10-12 days of incubation. Exploded eggs in the setter will facilitate dissemination of bacteria and molds and result in contamination to other eggs and to recently hatched chicks in the setter.

\section{Frequent Egg Gathering}

To reduce the incidence of floor eggs and cracks and produce cleaner and higher quality eggs, fertile eggs must be collected at least 4 to 6 times per day.
Eggs must be collected more frequently in the morning when $75 \%$ of the eggs are being laid and more frequently on days when temperatures are excessively high.

\section{Egg Transport Management}

It makes little economic sense to produce high quality, clean eggs at the farms, but then improperly transport them along rough roads, using inexperienced/unmotivated drivers, and poorly ventilated egg trucks with worn out suspension systems. The egg carts should be well cushioned and stable while the eggs are being transported. Avoid temperature shocks when the eggs are being transferred outside or inside. Responsible drivers should be found who understand the importance of their job and will ensure eggs are cared for during transport. Condition of the transport vehicles should be maintained. Remember that when the fertile egg is laid, it is a live organism and has already developed to the gastrula stage consisting of 20,000 to 40,000 cells! The minor deficiencies in egg management described above are cumulative and will result in loss of broiler meat produced per hen.

\section{Maintain High Fertility Level}

Fertility rate should be routinely monitored by candling a sample of eggs from each breeder flock at 7 to 12 days of incubation. If fertility is decreasing or is below standard, the problem must be investigated. A common practice to maintain fertility levels in aging flocks is to spike breeder flocks at 40 to 50 weeks of age with 30-35-week-old roosters. In the authors' experiences, spiking with young roosters has been shown to produce an improvement in percent hatchability by $1-2 \%$, and even resulted in improved broiler performance. Intra-spiking should also be considered.

\section{Egg Holding Duration}

Duration of storage of hatching eggs can have a dramatic impact on percent hatchability. The results of two large studies, conducted by the authors, demonstrated that fertile eggs held under recommended conditions of temperature and humidity completely failed to hatch when held in storage for more than 25 days. Even after 7 days 
storage, a significant reduction in hatchability was noted (Table 1). To achieve maximum percent hatch, the authors recommend to store eggs not more than 3 days in the egg room and maintain the egg holding room at a temperature of $65^{\circ} \mathrm{F}$ and relative humidity (RH\%) of approximately $78 \%$. These temperatures and RH\% settings need to be adjusted when egg storage periods are prolonged in an effort to conserve the internal integrity of the eggs. As a rule of thumb, as the egg storage time increases, storage room temperature should be decreased and the relative humidity increased to prevent dehydration.

Table 1. The effect of egg storage on $\%$ of hatchability.

\begin{tabular}{|c|c|c|}
\hline Days of storage & Trial 1 & Trial 2 \\
\hline 3 & 87 & 90 \\
\hline 8 & 70 & 76 \\
\hline 12 & 60 & 50 \\
\hline 16 & 26 & 17 \\
\hline 20 & 17 & 13 \\
\hline 23 & 7 & 3 \\
\hline $26-35$ & 0 & 0 \\
\hline
\end{tabular}

\section{Egg Storage Duration vs. Broiler Performance}

The hatchery managers must realize that as hatching eggs are held for longer times, the percent hatchability is decreased. Additionally, broiler performance is adversely affected in the field. In a trial where fertile eggs were held for 0,6 and 8 days in the egg room before incubation, the following results were obtained for the broiler males at 49 days of age (Table 2).

Table 2. Broiler performance influenced by storage time.

\begin{tabular}{|c|c|c|c|}
\hline Parameter & 0 day & 6 days & 8 days \\
\hline Body weight gr. & 2506 & 2470 & 2338 \\
\hline Conv. & 1.99 & 2.03 & 2.05 \\
\hline Daily gain gr. & 51.14 & 50.40 & 47.71 \\
\hline$\%$ Mort. & 3.33 & 6.67 & 10.00 \\
\hline Index & 248 & 232 & 210 \\
\hline
\end{tabular}

Significant reductions in most of the economically important performance parameters were clearly observed when eggs were held for extended periods, even under optimum holding conditions. The results of this study clearly demonstrate how decisions by the hatchery manager can influence the field performance parameters of the broiler.

\section{Egg Positioning During Storage and Setting}

A factor that significantly affects the percent hatch of fertile eggs and broiler performance in the field is positioning of the eggs during holding. Eggs must be incubated with the large end up; otherwise a dramatic reduction in percent hatch due to increased percent of mal-positions will occur. At the time of storage, if it is known that eggs are to be held for more than 7 days prior to setting, it is recommended to store eggs with the small end up. Then when placing them in the setter, reposition them with the large end up.

Two separate trials were conducted by the authors with more than 6,000 fertile eggs to determine the effect of egg storage position on percent of hatchability. Fertile eggs were kept for 7 days with Big End Up (BEU) or Small End Up (SEU). All eggs were obtained from the same flock, and were from the same day's production. All eggs were handled, cleaned, and disinfected in an identical manner. The results are provided below (Table 3 ).

These results clearly demonstrated a $2 \%$ improvement in hatchability when eggs are positioned with the SEU while in the egg storage room for 7 days. Positioning fertile eggs with the small end up, when holding times are prolonged, is not a new concept and has been routinely practiced in grand parent and turkey hatcheries. In practice, turning fertile eggs that are held for prolonged periods prevents the blastoderm on the yolk from sticking to the air cell, drying out and thus killing the embryo. Some hatchery managers, when there is an excess of eggs and holding times are prolonged, use the same turning devices used to move the eggs in the setter for the egg buggies while in the egg room. Other managers cover the eggs with a plastic sheet to reduce humidity loss from the eggs, which is estimated at $0.10 \%$ per day. The most logical and sound practice is to have a strict first-in, first-out program for preventing excess egg-holding times. Optimal egg collection, transport, storage management and egg 
Table 3. Effect of egg position storage on \% hatch.

\begin{tabular}{|c|c|c|c|}
\hline Trials & No. 1 & No. 2 & Total \\
\hline \# of eggs & 1426 & 4860 & 6286 \\
\hline Egg position & \multicolumn{3}{|c|}{$\%$ of hatchability } \\
\hline Big End Up & 85.55 & 84.28 & 85.22 \\
\hline Small End Up & 87.61 & 86.05 & 87.22 \\
\hline Diff. & 2.06 & 1.78 & 1.99 \\
\hline
\end{tabular}

handling will ultimately result in increased pounds of meat for sale at the end of the integration chain.

Results will vary depending on the operation, but between 2 to 10 more broilers per hen can be obtained with improved egg management. 